\title{
The relationship between the decrease in haemoglobin concentration and the volume of fluids administered during resuscitation from septic shock may not be so "weak"
}

Azriel Perel ${ }^{*}$ (D)

See related research by Maiden et al. https://ccforum.biomedcentral.com/articles/10.1186/s13054-018-2029-6

In a retrospective analysis of the database of the ARISE trial [1], Maiden et al. [2] found an independent though weak association between haemoglobin concentration $(\mathrm{Hgb})$ and the volume of fluids administered during resuscitation from septic shock. The volume infused accounted for less than $20 \%$ of the observed decrease in the $\mathrm{Hgb}$, but the explanations for this decrease, other than haemodilution, seem unlikely even to the authors themselves [2]. A closer look at this study suggests a much stronger association between the volume infused and $\mathrm{Hgb}$ decrease.

Of the 1600 ARISE patients, Maiden et al. excluded 281 who received blood transfusions [2]. It may well be that the transfused patients were those with the greatest degree of haemodilution, the low Hgb prompting the decision to transfuse. The data for these excluded patients might have shown a stronger association between volume infused and $\mathrm{Hgb}$ decrease. Of note, significantly more patients were transfused during the first $6 \mathrm{~h}$ in the EGDT group of the ARISE trial compared with the usual-care group [1]. A significant association between the amount of fluids and early blood transfusions was also recently reported in septic patients without shock [3].
Although the ARISE trial was not aimed at reporting Hgb values during the first $6 \mathrm{~h}$ of resuscitation, Maiden et al. report such values from roughly 200 patients [2]. Many of these patients seem to have had no fluids administered during the first hours, and yet have a significant decrease in $\mathrm{Hgb}$ of more than $2 \mathrm{~g} / \mathrm{dL}$ (Fig. 1). However, all patients in the ARISE trial received about $35 \mathrm{ml} / \mathrm{kg}$ prior to randomisation [1], a fact that explains the initial observed decrease in Hgb in Maiden et al.'s study [2]. Taking this significant amount of fluids into consideration when calculating the association between the infused fluids and Hgb decrease would have made this association much stronger.

Iatrogenic haemodilution is a possible complication of fluid administration [4]. Maiden et al. do indeed show that a greater decrease in Hgb was independently associated with increased duration of ventilation, length of ICU and hospital stay, and mortality [2]. When large amounts of fluids are given in order to maximise oxygen delivery, the resulting haemodilution may also lead to avoidable blood transfusions [5]. The data presented by Maiden et al. [2] do show that this is a real possibility during early resuscitation from septic shock. Tel Aviv, Israel 


\section{Authors' response}

\section{Matthew J. Maiden, Mark E. Finnis, Sandra Peake, Simon McRae, Anthony Delaney, Michael Bailey} and Rinaldo Bellomo

Intravenous fluids given to healthy volunteers [6] or administered during surgical procedures have been shown to cause haemodilution [5]. Hence, we too were somewhat surprised to observe a relatively weak (but statistically significant) association between the change in haemoglobin $(\mathrm{Hb})$ concentration and volume of intravenous fluids administered to patients resuscitated from septic shock. However, intravenous fluid may not induce the same degree of haemodilution in septic patients as healthy volunteers or elective surgical patients, particularly given the intra- and extra-vascular fluid shifts that occur with endothelial dysfunction in sepsis.

We believe it unlikely that we missed identifying a stronger association between intravenous fluid volume and decline in haemoglobin. We analysed patients with complete data for haemoglobin and intravenous fluid volume at each time point in the ARISE trial $(N=1011$ at $24 \mathrm{~h}, N=990$ at $72 \mathrm{~h}$; Fig. 2 in [2]) and performed a sensitivity analysis using data available during the first $6 \mathrm{~h}$ of resuscitation ( $N=788$; Fig. 1) [2]. All patients received intravenous fluids, and haemoglobin declined even in those who received a small volume of fluid. Many clinical factors that may have been confounders for this association were considered, but these had only a marginal influence. Furthermore, our findings are consistent with earlier (albeit smaller) clinical studies investigating the same relationship in critical illness $[7,8]$.
We are unable to contribute to the hypothesis that patients in ARISE may have been transfused red cells due to intravenous fluid induced haemodilution. Firstly, we considered haemoglobin concentration an independent variable and transfused patients $(281 / 1600,17.6 \%)$ were excluded, as supplementing red cells would have confounded the analysis. Secondly, patients who received red cells were anaemic at study enrolment (median $\mathrm{Hb}$ g/L; 98 [83-116] vs 133 [118-146], $P<0.001)$ while having received similar volume of fluids prior to enrolment (median L; 2.5 [1.7-3.3] vs 2.4 [2.0-3.3], $P=0.29$ ). Thirdly, when analysing the entire ARISE cohort and incorporating transfusion in multivariate analysis, the decline of haemoglobin with fluid volume was only marginally greater than described in the original analysis (change in $\mathrm{Hb}$ over $24 \mathrm{~h},-1.6 \mathrm{~g} \mathrm{Hb}$ per litre of fluid, $95 \% \mathrm{CI}-1.2$ to $-2.0, \mathrm{R}^{2}=11 \%, P<0.001$; change in $\mathrm{Hb}$ over $72 \mathrm{~h},-1.6 \mathrm{~g} \mathrm{Hb}$ per litre of fluid, $95 \% \mathrm{CI}-1.3$ to 1.9, $\mathrm{R}^{2}=26 \%, P<0.001$; Table 3 in [2]) [2]. Finally, incorporating the fluid volume administered prior to randomisation into this analysis made the association between haemoglobin and fluid volume weaker (change in $\mathrm{Hb}$ over $24 \mathrm{~h},-1.2 \mathrm{~g} \mathrm{Hb}$ per litre of fluid, 95\% CI 0.9 to $-1.6, P<0.001)$. The evidence that intravenous fluid causes clinically meaningful haemodilutional anaemia in septic shock remains weak, and other causes of the decline in haemoglobin should be considered.

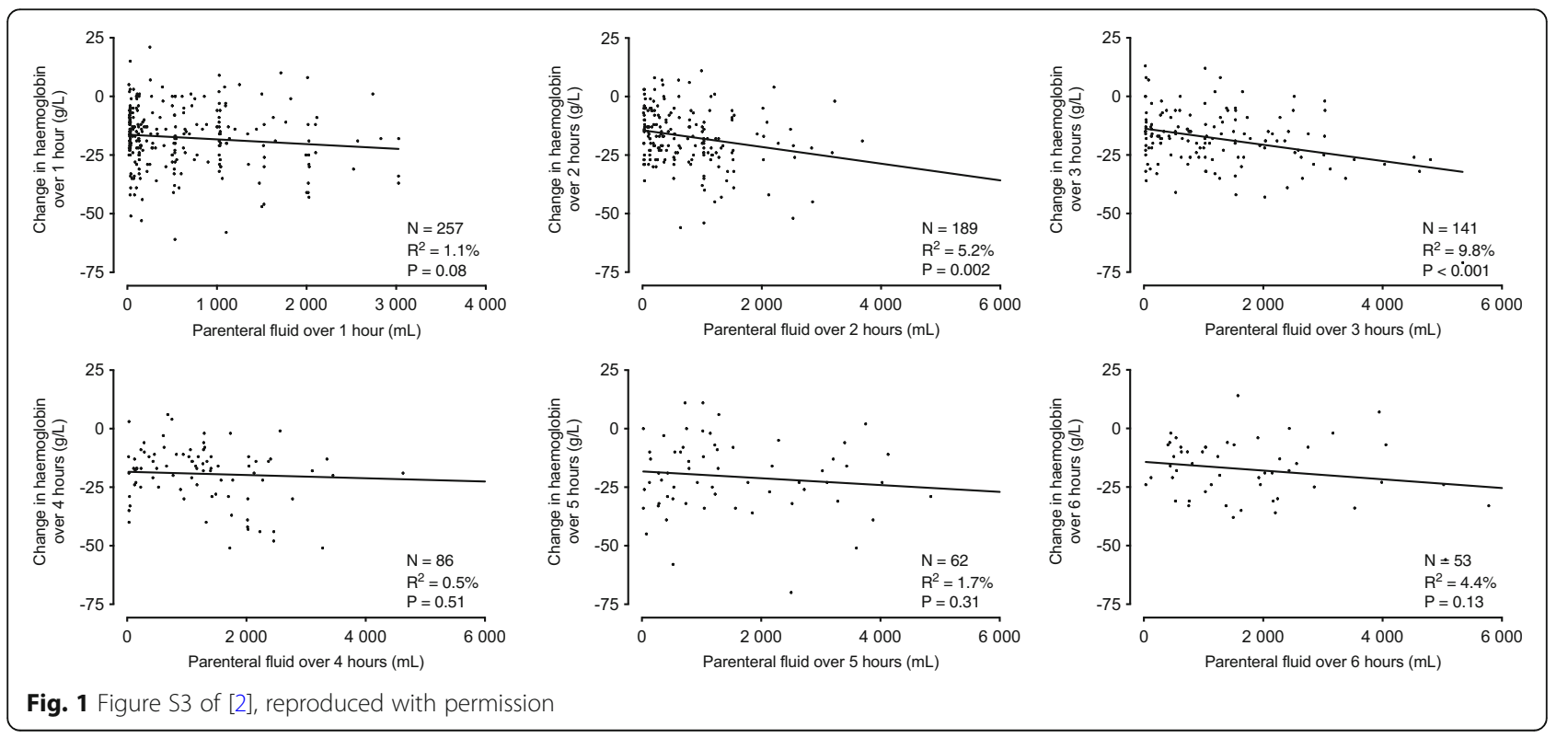




\section{Authors' contributions}

The author read and approved the final manuscript.

Ethics approval and consent to participate

Not applicable.

\section{Competing interests}

The author serves as an independent consultant to Masimo Inc., Irvine, CA, USA, and is a member of the medical advisory board of Pulsion/GETINGE,

Munich, Germany.

\section{Publisher's Note}

Springer Nature remains neutral with regard to jurisdictional claims in published maps and institutional affiliations.

Received: 25 May 2018 Accepted: 3 July 2018

Published online: 20 September 2018

\section{References}

1. Peake SL, Delaney A, Bailey M, Bellomo R, Cameron PA, Cooper DJ, et al Goal-directed resuscitation for patients with early septic shock. N Engl J Med. 2014:371:1496-506.

2. Maiden MJ, Finnis ME, Peake S, McRae S, Delaney A, Bailey M, Bellomo R Haemoglobin concentration and volume of intravenous fluids in septic shock in the ARISE trial. Crit Care. 2018;22:118.

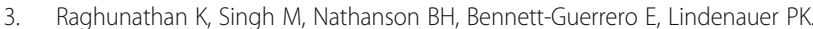
Early blood transfusions in Sepsis: unchanged survival and increased costs. Am J Crit Care. 2018;27:205-11.

4. Reuter DA, Chappell D, Perel A. The dark sides of fluid administration in the critically ill patient. Intensive Care Med. 2017; https://doi.org/10.1007/ s00134-017-4989-4.

5. Perel A. latrogenic hemodilution: a possible cause for avoidable blood transfusions? Crit Care. 2017:21:291.

6. Hahn RG, Svensen C. Plasma dilution and the rate of infusion of Ringer's solution. Br J Anaesth. 1997:79:64-7.

7. Jansma G, de Lange F, Kingma WP, Vellinga NA, Koopmans M, Kuiper MA, et al. 'Sepsis-related anemia' is absent at hospital presentation; a retrospective cohort analysis. BMC Anesthesiol. 2015;15:55.

8. Nguyen BV, Bota DP, Melot C, Vincent JL. Time course of hemoglobin concentrations in nonbleeding intensive care unit patients. Crit Care Med. 2003:31:406-10 